\title{
NORMATIVAS URBANAS NO BRASIL IMPERIAL: A CIDADE E A VIDA URBANA NA LEGISLAÇÃO BRASILEIRA $\left(1822\right.$ - 1850) ${ }^{1}$
}

\author{
URBAN NORMATIVES IN IMPERIAL BRAZIL: THE CITY AND URBAN \\ LIFE IN THE BRAZILIAN LEGISLATION (1822 - 1850)
}

\author{
Doralice Sátyro Maia \\ Doutorado em Geografia Humana \\ Universidade Federal da Paraíba \\ doralicemaia@hotmail.com
}

\begin{abstract}
RESUMO
A legislação brasileira no que diz respeito ao tratamento das suas cidades e da vida urbana no período imperial revela inspirações nos movimentos para a construção dos Estados Liberais ou do Novo Regime que se davam nos países europeus e nos Estados Unidos. Neste período, muito embora existissem as resoluções municipais, estas eram na maioria das vezes determinadas pela legislação nacional. O propósito deste artigo é mostrar como a cidade e a vida urbana foram regulamentadas pelas leis e pelos decretos que compuseram a Legislação Brasileira, particularmente na primeira metade do século XIX a partir da instalação do que se denomina Brasil Imperial. Desta forma, o intervalo temporal corresponde ao período de 1822 a 1850. A opção por este recorte deu-se em função da preocupação por demonstrar como a legislação brasileira vai redefinindo os regulamentos, as normativas e mesmo o tratamento da cidade e do urbano desde a instalação de uma nova forma de governar e também da construção do Estado Brasileiro. Já a definição do marco final - 1850 -, legitima-se em função da aprovação da Lei de Terras que provocará a partir de então grandes alterações no tratamento da terra tanto rural como urbana e, por conseguinte, do solo urbano com a instituição da propriedade privada. Primeiramente expõe-se a opção metodológica por analisar os documentos oficiais e posteriormente elege-se para análise as principais legislações que tratam da forma administrativa do espaço citadino e particularmente dos documentos que se referem às atribuições das Câmaras Municipais e, por conseguinte, das Posturas Municipais.
\end{abstract}

Palavras-Chave: Geografia Histórica Urbana; Normativas Urbanas; Brasil Imperial; Legislação Brasileira; Cidade do Século XIX.

\begin{abstract}
The Brazilian Legislation, where the treatment towards its cities and urban life is concerned over the imperial period, reveals inspirations in the movements for the construction of the Liberal States or the New Regime, which took place in the European countries and in the United States. In this period, despite the municipal resolutions, these were mostly determined by the national legislation. The main purpose of this article is to show how the city and urban life were regulated by laws and decrees of which the Brazilian Legislation was made up, especially in the first half of the $19^{\text {th }}$ century as of the establishment of the so-called Imperial Brazil. Thus, the temporal
\end{abstract}

Geo UERJ. Rio de Janeiro - Ano 16, no. 25, v.2, $2^{\circ}$ semestre de 2014, pp.458-476

ISSN: 1415-7543 E-ISSN: 1981-9021

http://www.e-publicacoes.uerj.br/index.php/geouerj 
interval corresponds to the period from 1822 to 1850 . The option to bring up this issue was due to the concern to show how the Brazilian legislation has been redefining regulations, norms, and even the treatment towards the city and the citizen as of the settlement of a new form of government and the construction of the Brazilian State. Taking the definition of the final mark into consideration -1850-, it is legitimized owing to the approval of the Law of Lands which will since then lead to great alterations in the treatment of both rural and urban land, and, as a consequence, of the urban soil due to the establishment of private properties. Firstly, we expose the methodological option by analyzing the official documents, and secondly, we choose, for analysis, the main legislations that deal administratively with city space, and particularly with documents which refer to the attributions of the City Councils, and, consequently, with Municipal Postures.

Key-words: Urban History Geography; Urban Norms; Imperial Brazil; Brazilian Legislation; 19th century City.

\section{Introdução}

O século XIX representa um momento bastante singular para o entendimento do processo de urbanização e principalmente do ordenamento urbano. No Brasil, se o ideário da Modernidade já se fazia presente no imaginário da elite e principalmente dos seus governantes, é também neste período que, “o pensamento higienista, que já se projetava na Europa há algum tempo, vai também fincar as suas bases no Brasil", quando se adotará uma polícia médica para as áreas urbanas (ABREU, 1997, p.38). Além disso, é no século XIX que os governos municipais ganham maior importância para o tratamento urbano. Por conseguinte, tais ideais e decisões políticas se farão presentes na legislação nacional brasileira, que terá como objetivo a regularização do governo imperial que se inicia em 1822.

A legislação brasileira no que diz respeito ao tratamento das cidades e da vida urbana no período imperial, quando se principiam os movimentos para a construção dos Estados Liberais ou do Novo Regime, contém elementos inspirados na maioria das vezes nas legislações de outros países, especialmente Inglaterra, França e Estados Unidos. Neste período, muito embora existissem as resoluções municipais, estas eram na maioria das vezes determinadas pela legislação nacional. O nosso propósito é mostrar como a cidade e a vida urbana foram regulamentadas pelas leis e pelos decretos que compuseram a Legislação Brasileira, particularmente na primeira metade do século XIX a partir da instalação do que se denomina Brasil Imperial, portanto, trataremos do intervalo 
temporal 1822 - 1850. A opção por este recorte deu-se em função da preocupação por demonstrar como a legislação brasileira vai redefinindo os regulamentos, as normativas e mesmo o tratamento da cidade e do urbano desde a instalação de uma nova forma de governar e também da construção do Estado Brasileiro. Já a definição do marco final 1850 -, legitima-se em função da aprovação da Lei de Terras que provocará a partir de então grandes alterações no tratamento da terra tanto rural como urbana e, por conseguinte, do solo urbano com a instituição da propriedade privada. Por fim, justificase o recorte temporal pelo "fôlego" possível para analisar o conjunto de documentos encontrados no decorrer do século XIX.

Sabe-se que nas principais cidades brasileiras, grandes mudanças acontecem a partir do século XIX, tais como o aumento demográfico, a institucionalização da propriedade privada, as melhorias de transporte e de infraestrutura urbana, tais como a instalação da iluminação, do abastecimento d'água, ou ainda o início da promoção imobiliária. Além disso, é nos primórdios do século XIX, que surge o regime administrativo criado pelos franceses e que se propagará pelo mundo. Destacamos que nesse período há também conversão de mentalidade, da vida social e ainda dos processos de organização administrativa. Tal assertiva complementa-se ao que escreve Horacio Capel:

El poder de la administración estatal (del gobierno central y de los gobiernos provinciales) sobre los municipios se afianzó durante el siglo XIX, ya que muchos Estados liberales acostumbraban a considerar a los municipios como el ultimo escalón de la administración del Estado (CAPEL, 2006, p. 9).

Observa-se, portanto, um movimento geral de conformação de uma organização política administrativa nos Estados nacionais que se encontram em formação ou solidifacação. Tal fato revela uma das ações que impulsionam a consolidação do modo de produção capitalista exige mudanças jurídicas e a instituição do Estado Nação. Muito embora existisse desde meados do século XVII ${ }^{2}$, é a partir da Revolução Francesa (1789), que a idéia de Estado Nação "espalha-se pelo mundo". O fundamento do Estado Nação é a riqueza mobiliária (dinheiro e capital), a terra e a renda da terra, portanto, a propriedade privada.

Já se conhece também que a criação de instituições e a aprovação de novas leis simbolizavam vitórias dos governantes e também a força do Estado desde o 
Renascimento. A partir da instituição do Estado Moderno cria-se o sistema de direito uniforme e de leis gerais para todo o território nacional. Desde então se concebe a lei como o instrumento político e jurídico que representará "uma missão grandiosa para qualquer chefe político"; portanto a sua análise permitirá compreender "o primeiro dos pilares do Estado moderno" (HOMEM, 2006, p.35). Assim, a legislação pode ser utilizada enquanto instrumento de análise, entendendo a importância da mesma para a construção do Estado do Brasil a partir dos anos vinte do século XIX e também para a ordenação e o disciplinamento das cidades e da vida urbana que começam a ganhar maiores proporções e importância. Neste sentido, serão apresentados alguns instrumentos normativos da Legislação brasileira do século XIX elaborados no intuito de ordenar, disciplinar e instruir a vida urbana em um território onde se aspirava pela consolidação do Estado moderno ${ }^{3}$ e, por conseguinte pela cidade moderna como conformação socioespacial desta forma de organização do poder.

A discussão apresenta-se em dois momentos. No primeiro discorre-se a respeito da utilização das leis, dos decretos e das resoluções, ou em outras palavras, da utilização de instrumentos legais e oficiais do Estado brasileiro no século XIX para o estudo da história da cidade e do urbanismo considerando-se a mentalidade enquanto conceito fundamental para a análise; no segundo serão citados alguns dos documentos pesquisados - leis, decretos e resoluções - que se referem à administração das cidades e da vida urbana no Brasil Imperial.

\section{Leis, decretos e resoluções: fontes para o estudo da história da cidade e do urbanismo}

As leis, os decretos, as resoluções e ainda as decisões executivas são denominações dadas aos documentos que constituem o conjunto das legislações do Brasil no século XIX. Aqui utilizamos a expressão "documento" para designar o tipo de material utilizado em nossa pesquisa. O termo provém da palavra latina dommentum e deriva de outra, docere, que por sua vez significa ensinar, é bastante utilizado no vocabulário legislativo. Na história positivista serviu de instrumento de pesquisa por seu sentido de "prova", muito embora fosse uma escolha do historiador. Contudo, sabe-se que o “documento" é resultado de uma criação ou mesmo de uma invenção, 
[...] un montaje, consciente o inconsciente, de la historia, de la época, de la sociedad que lo han producido, pero también de la épocas ulteriores durante las cuales ha continuado viviendo, acaso olvidado, durante las cuales ha continuado siendo manipulado, a pesar del silencio. El documento es una cosa que queda, que dura y el testimonio, la enseñanza (apelando a su etimología) que aporta, deben ser en primer lugar analizados desmitificando el significado aparente de aquél. El documento es monumento. Es el resultado del esfuerzo cumplido por las sociedades históricas por imponer al futuro - queriendo o no queriéndolo - aquella imagen dada de sí mismas. En definitiva, no existe un documento-verdad. Todo documento es mentira. Corresponde al historiador no hacerse el ingenuo (LE GOFF, 1991, p.238).

Com base nos escritos de Jacques Le Goff (1980, 1997), George Duby (1984), Edward Thompson (2002), entre outros, utilizamos as legislações nacionais do Brasil no século XIX como instrumentos de análise sabendo dos riscos e das incertezas que estes recursos podem implicar, mas também conscientes de que as suas afirmativas não significam a verdade, nem são provas dos fatos, mas que correspondem a uma fresta ou uma face da história e, portanto, da realidade analisada.

A respeito da análise das leis fora do campo jurídico, mais precisamente em pesquisas das ciências sociais, muito já se discutiu, sendo debate freqüente dos historiadores. Um argumento habitual que se contrapõe à utilização deste instrumento para o entendimento da realidade social é que a lei não necessariamente se concretiza e que, por conseguinte, não corresponde à realidade. Mesmo considerando essa afirmativa como fato, isto não significa aceitar a inviabilidade ou a não importância do estudo das legislações para se compreender dada sociedade ou realidade. Um outro argumento contrário ao uso das leis como instrumento de análise é o de que a lei é um instrumento da classe dominante e por isto mascara os conflitos sociais. Estamos cientes de que

[...] la ley, quizá más claramente que cualquier otra elaboración cultural o institucional, forma parte por definición de una <<superestructura>> que se adapta a las necesidades de una infraestructura de fuerzas productivas y de relaciones de producción. En cuanto tal es a todas luces un instrumento de la clase que es de hecho la dominante: define y a la vez defiende las exigencias de los dominantes en lo referente a recursos y a 
fuerza de trabajo - dice qué es propiedad y qué es delito - y media en las relaciones de clase con una serie de normas y sanciones oportunas, todas las cuales, a fin de cuentas, confirman y consolidan el vigente poder de clase. Así pues el imperio de la ley no es sino otra máscara del dominio de una clase (THOMPSON, 2002, p. 495).

Contudo, como qualquer instrumento de análise é preciso conhecer os riscos, as imperfeições e as impossibilidades da sua utilização ao se eleger os procedimentos metodológicos. Em qualquer pesquisa, a escolha dos elementos e dos instrumentos metodológicos requer conhecimento das suas limitações. Portanto, sabemos que ao conhecer e analisar a legislação brasileira da primeira metade do século XIX, estaremos revelando uma parte da história desse país, mas não a sua realidade.

Dessa forma, a primeira assertiva de que lei = classe dominante, pode restringir e subjugar a análise que não é tão simples e nem linear, mas sim, complexa e contraditória. Pois, se por um lado é certo que a lei intermedeia as relações de classe em benefício da classe dominante, por outro, ela também intervém nessas relações através dos registros legais que serviram muitas vezes para inibir as ações dos mesmos dominantes. (THOMPSON, 2002, p. 501).

É preciso lembrar que um documento, no sentido mais amplo do termo, mesmo que expresse o pensamento de uma classe, ele pode revelar o ideário e mesmo a mentalidade de uma época. No caso das leis, estas adquirem força maior na passagem "da esfera da legimidade para a esfera da legalidade" que marca a fase do Estado moderno no período pós Revolução Industrial, ou seja, a do Estado de direito. Estado este, segundo Pierangelo Schiera,

[...] fundado sobre a liberdade política (não apenas privada) e sobre a igualdade de participação (e não apenas pré-estatal) dos cidadãos (não mais súditos) frente ao poder, mas gerentciado pela burguesia como classes dominantes, com os instrumentos científicos fornecidos pelo direito e pela economia na idade triunfal da Revolução Industrial. (SHIERA In: BOBBIO, 1986, p. 430).

As leis, portanto, necessitam apresentar princípios de equidade y universalidade e que consequentemente, ou mesmo "forzosamente hubieron de extenderse a todo tipo y rango de hombres." ${ }^{4}$ Assim, podemos afirmar que a análise do conjunto de leis possibilita a compreensão do "espírito" ou da "mentalidade" da época. Conceitos profundamente 
tratados pela História oferecem fundamentos às nossas interpretações, mas também expõem as limitações e os riscos à derivações, pois, "considerar como unidad una realidad compleja y estructurada, si no en clases al menos en categorías sociales diferentes por sus intereses y su cultura, suponer un «espíritu del tiempo» (Zeitgeist), esto es, un inconsciente colectivo; se trata de peligrosas abstracciones" (LE GOFF, 1997, p. 49).

Fazemos uso do conceito de "mentalidade", pois entendemos que o mesmo expressa um dos nossos pressupostos: de que a elaboração das legislações do Brasil na primeira metade do século XIX, mais exatamente aquelas que se referem ao tratamento do espaço urbano revelam um "espírito do tempo" ou uma mentalidade da época 5 .

A partir do entendimento sobre a utilização da legislação enquanto fonte documental de pesquisa, tornou-se indispensável a compreensão da mentalidade da época. Para isto necesitamos, como adverte Le Goff, "ante todo, operar una cierta lectura de un documento, sea cual sea" (LE GOFF, 1980, p. 91). E como já frisamos, os nossos documentos correspondem à legislação brasileira no período imperial que trataram da cidade e da vida urbana. Embora possamos mencionar alguns fatos ou registros legais de períodos anteriores ou posteriores que mereçam ser destacados, o nosso recorte temporal abrange parte do período imperial (1822 - 1850). Interessa-nos particularmente os documentos que se referem à regulamentação dos princípios e das normas tendo em vista o ordenamento da estrutura das cidades e da vida urbana.

No período analisado, uma das idéias mais evidentes no conjunto de leis, decretos e decisões reais promulgado pelo Estado Brasileiro é o da eliminação das monarquias absolutistas, defendendo a monarquia constitucional baseada em uma oligarquia de proprietários de terras, mas que se expressa por uma assembléia representativa. Esta forma governativa mostrou-se no século XIX mais adequada aos interesses da burguesia liberal do que a república democrática. A mesma propaga-se pelos mais diversos territórios e, por conseguinte, representará os ideais da sociedade moderna (HOBSBAWM, 2001, p. 67).

Assim é que em 1822 no Brasil promulga-se a primeira Constituição instalando em seu território o modelo liberal de Estado. (Figura 1). Além dos textos constitucionais, o conjunto de leis e decretos também se inspirará nos ideais liberais e impulsionará as mudanças necessárias à consolidação do capitalismo. Por conseguinte, tais normativas 
repercutirão na morfologia e no ordenamento urbano, uma vez que determinarão a forma de administrar as cidades. Assim, o que objetivamos neste artigo é revelar os principais ideais e as decisões governamentais do Brasil revelados pela legislação vigente no período analisado no sentido de instituir a forma administrativa das cidades.

\section{Figura 1}

\section{Constituição Brasileira - 1824}

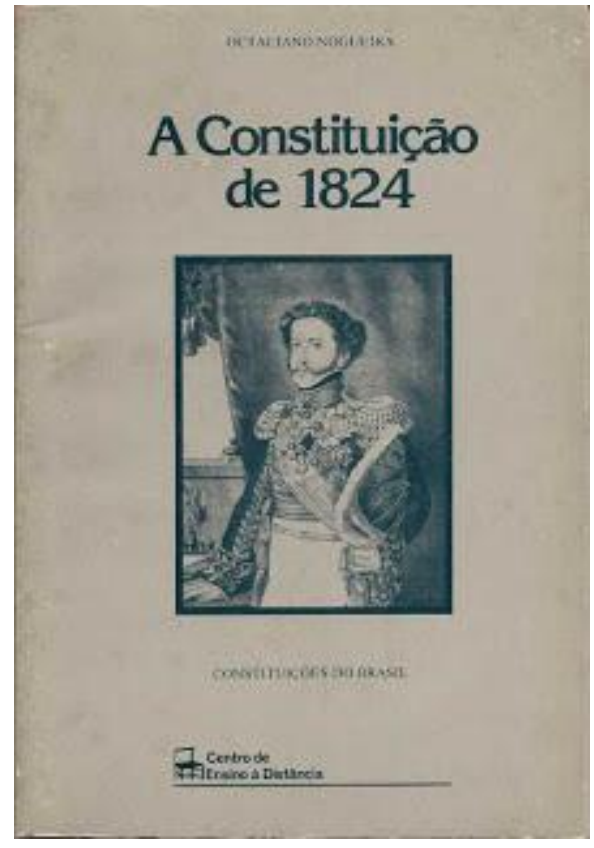

Fonte: http://www2.camara.gov.br [Acesso em 07 de abril de 2008].

A implementação ou não das leis, dos decretos e ainda das resoluções, bem como a sua eficiência poderão ser apontados, mas não constituem o nosso propósito, mesmo porque nos levaria a utilizar uma outra metodologia, outros instrumentos de análise e por fim, elaborar uma outra pesquisa.

\section{As leis, os decretos e as resoluções referentes à administração das cidades e da} vida urbana no Brasil Imperial

Na primeira metade dos oitocentos, em síntese, prevalecem no mundo duas tradições jurídicas: a inglesa caracterizada pelo common $\operatorname{law}^{6}$ e pela equidade e a francesa, formulada no momento da Revolução de 1789 e com forte influência das ideias de 
Rosseau. É a partir da Revolução Francesa que surge a Constituição como lei fundamental apta a limitar o poder dos dirigentes estatais. Limitação esta que se dá em benefício dos direitos, construídos no decurso histórico. No sistema jurídico francês e do seu constitucionalismo se valoriza a supremacia da lei. O caráter democrático e descentralizado que tanto caracteriza a forma de governar e defendido pelas denominadas constituições revolucionárias francesas (1791, 1793 e 1795) é substituído pelo centralismo napoleônico nas constituições de 1799, 1802 e 1804 e que a partir de 1830 sofre alterações, mantendo o caráter centralizador da máquina administrativa somada ao poder local representativo.

Esses dois sistemas jurídicos e administrativos sem dúvida inspiraram a construção dos sistemas jurídicos e a reforma administrativa em vários países. É o que verificamos a partir da leitura dos textos da constituição brasileira de 1824. Destacamos que o texto constitucional, assim como o conjunto de leis e decretos explicitam a centralização do poder estatal e a redefinição da forma administrativa no período imperial. Referente à administração local, um primeiro ponto a destacar é a preocupação por se determinar as cidades, aqueles núcleos que teriam as Câmaras Municipais.

A respeito da história administrativa brasileira é consenso o fato de que a partir de 1822 , com a Independência, as funções burocráticas e políticas ganham destaque. Mesmo assim, em 20 de outubro 1823, uma lei brasileira vigora as antigas Ordenações Filipinas, bem como todas as leis e os decretos promulgados pelos reis de Portugal até 25 de abril de 1821, enquanto não se organizasse um novo código.

A primeira - e única durante todo império - constituição brasileira de 1824 tem um título referente à administração e à economia das províncias e um capítulo dedicado à organização municipal, denominado "Das Comarcas" composto por três artigos, assim descritos:

Art. 167. em todas as Cidades ${ }^{7}$, e Villas ora existentes, e nas mais, que para o futuro se crearem haverá Câmaras, às quaes compete o Governo econômico, e municipal das mesmas Cidades, e Villas.

Art. 168. As Câmaras serão electivas, e compostas do numero de Vereadores, que a Lei designar, e o que obtiver maior numero de votos, será Presidente.

Art. 169. O exercício de suas funcções municipaes, formação das suas Posturas policiaes, applicação das suas rendas, e todas as suas particulares, e úteis attribuições, serão decretadas por 
uma Lei regulamentar. (CONSTITUIÇÃO POLÍTICA DO BRASIL, 1824).

Sobre esse texto, Raymundo Faoro argumenta que "o espírito da independência, com o estímulo prestado pelas câmaras locais ao príncipe, a aprovação do texto constitucional por elas, fariam supor que o espírito municipal conquistaria lugar de relevo nas novas instituições políticas" (FAORO, 1987, p. 305). Contudo, o que se verifica é a manutenção do poder central, atribuindo pouca autonomia às Câmaras Municipais.

A respeito da criação das vilas, o Decreto de 13 de Novembro de 1832 prescreve a maneira de se fazer efetiva a criação de uma vila. Diz:

Para se fazer effectiva a creação de uma Villa, será remettido o Decreto da sua creação, e a de designação dos limites do seu termo, à Câmara Municipal, á que pertencer o local da nova villa; a qual ordenará aos Juizes de Paz do novo termo que procedam á eleição dos Vereadores. ${ }^{8}$

O texto é complementado com outros parágrafos que definem os procedimentos dos Juizes de Paz e dos Vereadores.

Referente à administração territorial, verifica-se que a partir de 1831 são promulgados leis e decretos que estabelecem a divisão do território dos municípios e das cidades em "freguesias" e a compartimentação destas em partes e também em bairros. Isto se dá primeiramente na cidade do Rio de Janeiro e posteriormente se estende às outras cidades brasileiras. O primeiro documento encontrado data de 14 de Julho de 1831, Decisão n. 175 da Justiça que ordena a Câmara Municipal do Rio de Janeiro propor a divisão da cidade em quatro partes proporcionais à sua população e que fossem criados mais dois Juízes Criminais. Ainda em 1831, o Poder Executivo determina que a cidade do Rio de Janeiro seja dividida em quatro bairros com seus respectivos Juízes Criminais e que por sua vez terão os seus respectivos distritos e freguesias. Dois anos depois, a decisão de número 31 do Ministério do Império através do Edital de 25 de Janeiro de 1833 da Câmara Municipal do Rio de Janeiro divide a cidade em novas freguezias. Tal decisão dá-se em "conformidade ao Código do Processo Criminal e das suas respectivas instruções",

Todas as normativas acima apontadas mostram que o grande determinante para as divisões administrativas e territoriais da cidade do Rio de Janeiro e, por conseguinte, do que virá a ser na maior parte das cidades brasileiras do período estudado, é o jurídico.

Geo UERJ. Rio de Janeiro - Ano 16, no. 25, v.2, $2^{\circ}$ semestre de 2014, pp.458-476

ISSN: 1415-7543 E-ISSN: 1981-9021

http://www.e-publicacoes.uerj.br/index.php/geouerj 
Ou seja, a preocupação em melhor dividir as cidades para aprimorar as ações dos Juizes de Paz e Juizes Criminais que por sua vez estavam regulamentados pelo Código do Processo Criminal de Primeira Instância promulgado em $1832^{10}$. Mesmo entendendo que tais ordenações tiveram como determinante uma decisão judiciária ou dada em função dos processos criminais, essas compartimentações da cidade promovem, por sua vez, uma outra forma de administrar a cidade, atendendo aos princípios do que se pretende estabelecer: o Estado Brasileiro enquanto Estado moderno.

Ainda no Primeiro Império, as Câmaras Municipais vão ser regulamentadas e padronizadas para o tratamento do espaço urbano a partir da Carta de Lei de $1^{\circ}$ de outubro de 1828. Neste período, muito embora o poder estivesse centralizado, algumas determinações antes designadas pelo Império, passam a ser atribuições da Câmara Municipal. Contudo, as definições dadas por esta legislação ficaram aquém do texto constitucional e do espírito liberal: "Em lugar de uma célula viva, diretamente nascida da sociedade, associação superior à lei, [...] saiu um município tutelado", ou seja, “converte-se o município em peça do mecanismo central” (FAORO, 1987, p. 305).

Apesar da definição das atribuições das "Câmaras", percebe-se uma incongruência entre o que se determina e o que de fato se concretiza ou mesmo se pode efetivar. Pois, as decisões locais são controladas pelo governo central e, além disso, as unidades municipais possuem parcos recursos financeiros para viabilizarem todas as atribuições determinadas pelo texto constitucional e pelas leis complementares. No Brasil, os municípios teriam que atender às demandas de melhoramento urbano, de instrução, da saúde e policial, e os recursos eram por demais escassos. Desta forma, não se atendia às mínimas funções indispensáveis à manutenção dos seus serviços, e ainda estavam sujeitas "ao desconfiado e miúdo controle dos conselhos gerais das províncias, dos presidentes de províncias e do governo geral" (FAORO, 1987, p. 306).

Dessa forma, a centralização exercida pelo Estado que se mostra mais fortalecido no Antigo Regime, também não deixa de se fazer presente no Novo Regime revelando-se nas leis da primeira metade do século XIX. Guardadas as devidas diferenças, independente da posição política vigente, ou seja, nos regimes absolutistas ou nos governos constitucionais, fato é que no que se refere às normativas municipais, estas para se fazerem valer deveriam ser aprovadas em instâncias superiores e/ou seguir as determinações gerais dadas pelos governos reais. Deste modo, as "Câmaras Municipais" 
brasileiras, os organismos responsáveis pela administração das cidades, pelo ordenamento urbano e pelo disciplinamento da vida urbana estavam subordinadas ao Estado Central.

No conjunto das leis imperiais brasileiras, até o ano de 1850, encontramos alguns documentos bastante expressivos que tratam da regulamentação e das atribuições das Câmaras Municipais. (Quadro 1).

\section{Quadro 1 - Documentos Referentes Às Câmaras Municipais}

\begin{tabular}{|c|c|c|}
\hline $\begin{array}{l}\text { Número da lei } \\
\text { e/ou decreto/ } \\
\text { ministério }\end{array}$ & Data & Descrição \\
\hline N. 51 - Império & $\begin{array}{l}20 \text { de março de } \\
1829\end{array}$ & $\begin{array}{l}\text { Sobre esclarecimentos relativamente a } \\
\text { alguns pontos da lei da creação das Câmaras } \\
\text { Municipaes. }\end{array}$ \\
\hline N. 86 - Império & $\begin{array}{l}29 \text { de Março de } \\
1830\end{array}$ & $\begin{array}{l}\text { Sobre duvidas na execução da Lei do } 1 \text {. de } \\
\text { Outubro de } 1828 \text { das Câmaras Municipaes. }\end{array}$ \\
\hline N. 98 - Império & $\begin{array}{l}24 \text { de Abril de } \\
1830 .\end{array}$ & $\begin{array}{l}\text { Sobre a competência das Câmaras } \\
\text { Municipaes na verificação dos títulos para o } \\
\text { exercício da profissão de medico }\end{array}$ \\
\hline N. 230 - Império & $\begin{array}{l}14 \text { de Dezembro de } \\
1830\end{array}$ & $\begin{array}{l}\text { Sobre a obrigação das Câmaras Municipaes } \\
\text { de darem esclarecimentos aos Presidentes de } \\
\text { Províncias. }\end{array}$ \\
\hline N. 377 - Fazenda & $\begin{array}{l}15 \text { de novembro de } \\
1831\end{array}$ & $\begin{array}{l}\text { Manda que os Vereadores da Câmara } \\
\text { Municipal, que têm servido de Provedores } \\
\text { da Saúde Pública, prestem contas no } \\
\text { Thesouro Publico Nacional }\end{array}$ \\
\hline N. 69 - Justiça & $\begin{array}{l}11 \text { de Fevereiro de } \\
1832\end{array}$ & $\begin{array}{l}\text { Compete ás Câmaras Municipaes abrir e } \\
\text { guardar os Pelouros e dar posse aos Juizes } \\
\text { de Orphãos e Ordinários. }\end{array}$ \\
\hline N. 345 - Império & $\begin{array}{llll}28 & \text { de } & \text { Junho } \\
1833 & & \end{array}$ & $\begin{array}{l}\text { Declara á Câmara Municipal da Cidade de } \\
\text { Cabo Firo que não pode ser demolido o } \\
\text { Pelourinho existente na mesma cidade, sem } \\
\text { deliberação do Poder Legislativo. }\end{array}$ \\
\hline N. 151 - Justiça & $\begin{array}{l}28 \text { de } \text { Abril de } \\
1832\end{array}$ & $\begin{array}{l}\text { As Câmaras Municipaes não podem intervir } \\
\text { na formação dos Pelouros, que é da } \\
\text { competência dos Corregedores de comarca. }\end{array}$ \\
\hline N. 219 - Império & $\begin{array}{l}18 \text { de Julho de } \\
1832\end{array}$ & $\begin{array}{l}\text { Declara não haver incompatibilidade na } \\
\text { ccumulação dos cargos de Vereador da } \\
\text { Câmara Municipal e Collector da décima } \\
\text { urbana. }\end{array}$ \\
\hline N. 632 - Fazenda & $\begin{array}{l}22 \text { de Outubro de } \\
1833\end{array}$ & $\begin{array}{l}\text { Declara que á Câmara Municipal da Corte } \\
\text { pertence a numeração das casas para fins } \\
\text { policiaes. }\end{array}$ \\
\hline N. 715 - Justiça & 24 de Novembro de & Às Câmaras Municipaes pertence \\
\hline
\end{tabular}

Geo UERJ. Rio de Janeiro - Ano 16, no . 25, v.2, $2^{\circ}$ semestre de 2014, pp.458-476

ISSN: 1415-7543 E-ISSN: 1981-9021

http://www.e-publicacoes.uerj.br/index.php/geouerj 


\begin{tabular}{|c|c|c|}
\hline & 1833 & pagamento das despesas com as cadêas. \\
\hline Decreto N. 65 & $\begin{array}{l}9 \text { de } \text { Outubro de } \\
1835\end{array}$ & $\begin{array}{l}\text { Incorpora ao patrimônio da Câmara } \\
\text { Municipal da cidade do Rio de Janeiro as } \\
\text { bancas do pescado situadas na Praça do } \\
\text { Peixe. }\end{array}$ \\
\hline Decreto N. 83 & $\begin{array}{l}24 \text { de Julho de } \\
1850-\end{array}$ & $\begin{array}{l}\text { Declara não ser permittida á Illustrissima } \\
\text { Câmara Municipal alterar o nível das } \\
\text { calçadas, sem haver plano do nivelamento } \\
\text { da Cidade. }\end{array}$ \\
\hline
\end{tabular}

Fonte: Collecçao das Decisóes do Governo do Impèrio do Brazil de 1822- 1850. Rio de Janeiro: Typographia Nacional $1822-1850$.

A relação de determinações exposta no quadro 1, mostra que a legislação nacional apesar de expressar maiores determinações sobre a Câmara Municipal do Rio de Janeiro, já que esta era a corte imperial, muito diz sobre as suas atribuições de forma mais geral e que portanto deverão ser seguidas pelas demais Câmaras do território brasileiro. Além disso, vale lembrar que as ordenações atribuídas à Câmara do Rio de Janeiro serviam de parâmetro para as demais. Assim, tem-se desde as resoluções das atribuições e deveres dos seus representantes, ou seja, os vereadores (N. 377 - Fazenda e N. 219 - Império); às atribuições gerais das Câmaras Municipais (N. 98 - Império; N. 230 - Império; N. 69 - Justiça ; N. 632 - Fazenda; N. 715 - Justiça e Decreto N. 83). Dentre estas determinações cita-se: a competência para o pagamento das cadeias; a não permissão em alterar os níveis das calçadas sem respeitar um plano de nivelamento da Cidade; a numeração das casas; a guarda dos pelouros, bem como a não permissividade para formar pelouros. Sobre este conjunto de competências e não competências, é visível que neste período, o Estado Brasileiro tratava de definir as atribuições das suas instituições, então sob novo regime: o governo imperial. Além disso, como as Câmaras Municipais existiam desde o período colonial, algumas mudanças se faziam necessárias. Dentre estas destaca-se que já no início do século XIX, mais exatamente em 1828 no primeiro império, as Câmaras Municipais vão ser regulamentadas e padronizadas para o tratamento do espaço urbano a partir da carta de lei de $1^{\circ}$ de outubro de 1828 . O seu artigo 66 determina que tudo que diz respeito à gestão do chão público é de responsabilidade das câmaras. Cita "a questão do alinhamento das ruas, chães, e praças, da conservação e reparos de edifícios públicos, calçadas, pontes, fonte, aqueductos, chafarizes, poços, tanques, e quaesquer outras constucções em benefício commum dos habitantes, ou para decoro, e ornamento das Povoações" (Carta de lei de 1828). E ainda 
no parágrafo $2^{\circ}$ desse mesmo artigo, atribui também às câmaras o trato dos cemitérios. (id. Ibdem. ). Note-se aqui o início da passagem do poder religioso para o estatal. Muito embora o poder esteja centralizado, algumas determinações antes designadas pelo Império passam a ser atribuições da Câmara Municipal.

Ainda referente às atribuições das Câmaras Municipais, acrescentamos que no período imperial, cabia a essas a formulação e aaprovação das Posturas Municipais. Como bem escreve Murilo Marx ( 1999, p.42), elevada "uma sede de freguesia a vila, esta e as demais povoações de ser termo passariam a merecer, se não maiores, pelo menos outros cuidados temporais para com a vida e o espaço comum, as posturas municipais". Portanto, as Posturas Municipais constituiam o principal documento das cidades brasileiras. A elaboração destas e a fiscalização do seu cumprimento também era função das Câmaras Municipais ${ }^{11}$. Dada a sua importância no que se refere à legislação urbana, optamos por reunir os documentos referentes à criação, à fiscalização e às alterações nas posturas em um quadro específico (Quadro 2).

\section{Quadro 2 - Legislação do Império Brasileiro referente às Posturas Municipais}

$(\mathbf{1 8 2 2}-\mathbf{1 8 5 0})$

\begin{tabular}{|l|l|l|}
\hline $\begin{array}{l}\text { Número } \\
\text { ministério }\end{array}$ & Data & Descrição \\
\hline $\begin{array}{l}\text { N. 110 } \\
\text { Império }\end{array}$ & $\begin{array}{l}19 \text { de Junho de } \\
1829\end{array}$ & $\begin{array}{l}\text { Sobre a autoridade competente para approvar ou } \\
\text { reprovar as posturas municipaes, e a respeito da } \\
\text { commulação da pena de multa em dias de prisão. }\end{array}$ \\
\hline Decreto s/n & $\begin{array}{l}\text { De } 24 \text { de } \\
\text { Setembro de } \\
1830\end{array}$ & $\begin{array}{l}\text { Determina que tenham vigor por mais um anno as } \\
\text { posturas das Câmaras Municipaes. }\end{array}$ \\
\hline $\begin{array}{l}17 \text { de agosto de } \\
\text { Império }\end{array}$ & $\begin{array}{l}1831 \\
\text { Declara que os Presidentes nenhuma ingerência } \\
\text { têm nas posturas das Câmaras Municipaes. }\end{array}$ \\
\hline Decreto s/n & $\begin{array}{l}25 \text { de Outubro } \\
\text { de } 1831-\end{array}$ & $\begin{array}{l}\text { Prohibe a execução de posturas municipaes antes } \\
\text { de sua approvação. }\end{array}$ \\
\hline $\begin{array}{l}29 \text { de Novembro } \\
\text { Império } 1831\end{array}$ & $\begin{array}{l}\text { Manda executar provisoriamente as posturas da } \\
\text { Câmara Municipal da Corte sobre espectaculos } \\
\text { públicos. }\end{array}$ \\
\hline N. 44 - Império & $\begin{array}{l}28 \text { de Janeiro de } \\
1832\end{array}$ & $\begin{array}{l}\text { Approva interinamente as Posturas organizadas } \\
\text { pela Câmara Municipal da Corte em 4 de Outubro } \\
\text { de 1830. }\end{array}$ \\
\hline Decreto N. 256 & $\begin{array}{l}30 \text { de Novembro } \\
\text { de 1841 }\end{array}$ & $\begin{array}{l}\text { Manda ficar sem effeito a disposição do do } \\
\text { Paragrapho quarto, Titulo sexto, Secção primeira } \\
\text { das Posturas da Câmara Municipal desta Corte na }\end{array}$ \\
\hline
\end{tabular}

Geo UERJ. Rio de Janeiro - Ano 16, no. 25, v.2, $2^{\circ}$ semestre de 2014, pp.458-476

ISSN: 1415-7543 E-ISSN: 1981-9021

http://www.e-publicacoes.uerj.br/index.php/geouerj 


\begin{tabular}{|l|l|l|}
\hline & & $\begin{array}{l}\text { parte, que respeita ás Officinas dos Ferreiros, } \\
\text { Caldeireiros, Tanoeiros, e Serralheiros. }\end{array}$ \\
\hline Decreto N. 339 & $\begin{array}{l}26 \text { de Fevereiro } \\
\text { de } 1845\end{array}$ & $\begin{array}{l}\text { Declara que fica sem rigor a disposição dos } \\
\text { paragraphos segundo e quarto, do Titulo sexto, } \\
\text { Secção primeira, das Posturas da Câmara } \\
\text { Municipal do Rio de Janeiro, na parte que obriga } \\
\text { os Fabricantes de Tabaco a transferir suas fabricas } \\
\text { dos lugares onde actualmente se achão } \\
\text { estabelecidos. }\end{array}$ \\
\hline
\end{tabular}

Fonte: Collecçao das Decisóes do Governo do Impèrio do Brazil de 1822- 1850. Rio de Janeiro: Typographia Nacional $1822-1850$.

No Quadro 2, observa-se que desde a determinação de vigência das Posturas Municipais - de um mínimo de um ano - à não ingerência do Presidente da Câmara sobre as determinações das posturas, foram necessárias ordenanças nacionais. Há, portanto, na primeira metade do século XIX a preocupação por regulamentar e aplicar as posturas municipais aprovadas nas suas respectivas Câmaras Municipais. Nota-se também que estes documentos sofriam algumas alterações no decorrer do tempo em função das novas necessidades urbanas, tanto no que diz respeito à morfologia urbana como também à normatização da vida urbana que se despontava. Por outro lado, também era comum tornar sem validade algumas determinações, este é o exemplo do Decreto N. 339 de 26 de fevereiro de 1845 , assim escrito:

Declara que fica sem rigor a disposição dos paragraphos segundo e quarto, do Titulo sexto, Secção primeira, das Posturas da Câmara Municipal do Rio de Janeiro, na parte que obriga os Fabricantes de Tabaco a transferir suas fabricas dos lugares onde actualmente se achão estabelecidos ${ }^{12}$.

No mesmo sentido, o Decreto n. 256 de 30 de novembro de 1841 "Manda ficar sem effeito a disposição do Paragrapho quarto, Titulo sexto, Secção primeira das Posturas da Câmara Municipal desta Corte na parte, que respeita às Officinas dos Ferreiros, Caldeireiros, Tanoeiros, e Serralheiros" ${ }^{13}$. (Figura 2).

Figura 2

Código de Posturas - Cidade do Rio de Janeiro 


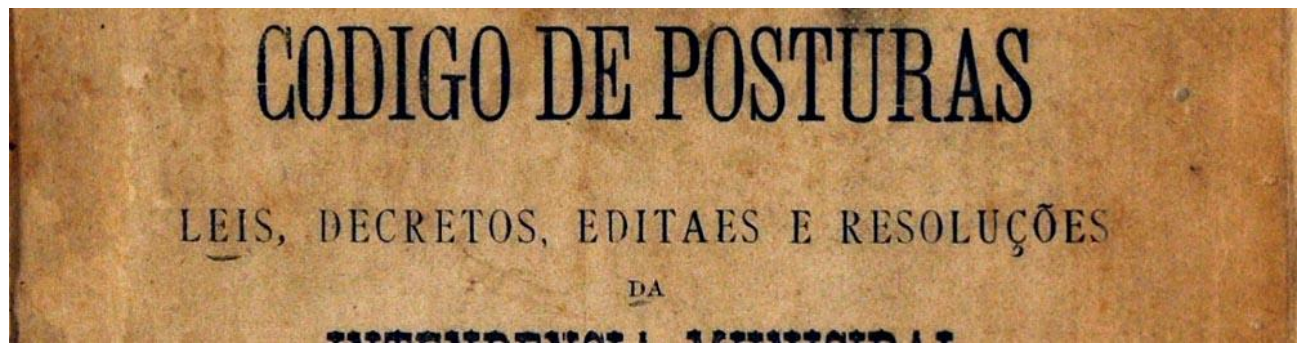

Fonte: http://www0.rio.ri.gov.br/arquivo/acervos-biblioteca.html [ Acesso em 30 de outubro de 2014].

Sobre as Posturas Municipais é necessário entender a sua importância. Trata-se de um conjunto de normas e preceitos estabelecido pela Câmara Municipal "que obriga os municípios a cumprirem certos deveres de ordem pública, especialmente aqueles ligados à organização, ao disciplinamento e à construção do espaço da cidade." (SOUZA, 2002, p. 2). Essas normativas representam a necessidade que os governantes da época tinham em disciplinar a expansão da cidade, bem como a conduta dos seus habitantes. Se desde o período colonial, o Código Geral de Posturas Municipais expressava a necessidade de se marcar a praça, as ruas e os rocios, no período imperial as mesmas sofrerão mudanças, contudo sem alterar os seus objetivos, ou seja, o de definir o ordenamento das cidades e a conduta da vida urbana. Apesar das modificações que ocorrem no decurso temporal, especialmente a partir da instalação do governo imperial, as Posturas Municipais determinam as formas que vão se expressar nas transformações da paisagem urbana e também os princípios que regerão a vida dos citadinos: os horários festivos e de trabalho; os locais de encontro; a forma de caminhar ou cavalgar pelas ruas da cidade; os locais para festejos, entre outros. Trata-se, como bem demonstrou Sousa (2002), do principal documento da cidade brasileira na primeira metade do século XIX.

\section{Outras Considerações}

A pesquisa documental sobre o conjunto legislativo brasileiro do século XIX mostrouse relevante para a compreensão da cidade e da vida urbana no período em destaque. Procurou-se neste artigo indicar as principais determinações que compõem o conjunto de leis, decretos e resoluções promulgados pelo Estado brasileiro e que incidiam 
diretamente sobre a normatização da estrutura, da organização e do disciplinamento das cidades e, por conseguinte da vida urbana que se principiava. Muito embora se trate de instrumentos ou fontes de pesquisa mais utilizadas por outros campos do saber, reconhece-se a sua importância para a geografia, seja para a geografia política, seja, para a geografia histórica e/ou mais propriamente para a geografia histórica urbana que é o viés que diretamente nos interessa.

Há de se registrar que existe um outro conjunto de leis, decretos e decisões nacionais do mesmo período que implicam diretamente na vida urbana e na estrutura das cidades. Trata-se de determinações que expressam a preocupação com a segurança e com a tranquilidade pública, encontrada especialmente nas decisões do Ministério da Justiça. Merece destaque ainda as decisões e leis que autorizam a realização de obras públicas, muitas delas referentes aos equipamentos urbanos e aos serviços urbanos ou às melhorias nas ruas, nas calçadas, nas praças e nos prédios públicos. Contudo, a análise dessas legislações só será possível em outro momento por implicar a concretude de outra etapa de análise. Além disso, registra-se o conjunto de legislações que autorizaram, bem como regularizaram os serviços dos profissionais que deveriam ser contratados para o controle da saúde, da higiene e também para a formulação dos planos das cidades, a exemplo dos médicos e engenheiros. ${ }^{14}$

Por fim, vale destacar a importância da análise dos documentos oficiais, a exemplo das leis, decretos e resoluções que compõem a legislação nacional para a compreensão da história da cidade e da vida urbana brasileira na primeira metade do século XIX.

\section{Notas}

\footnotetext{
1 Artigo originalmente produzido enquanto resultado de estágio de Pós-Doutorado realizado na Universidad de Barcelona (UB) no período de setembro de 2006 a agosto de 2007 sob a supervisão do Prof.. Dr. Horacio Capel e com financiamento do CNPq (Bolsa de Pós-Doutorado Exterior). Texto apresentado com o título "A Legislação Brasileira e o Tratamento da Cidade e da Vida Urbana no período imperial", no Seminário de História da Cidade e do Urbanismo de 2008 na cidade do Recife-PE. Posteriormente publicado nas atas do evento: v. 10, n. 3, 2008.

2 Atribui-se à criação do Estado Nação ao tratado de Westfalia de 24 de outubro de 1648 assinado pelos países França, Espanha, Países Baixos, Sacro Império Romano Germânico, Suécia e Dinamarca, para por fim a denominada guerra dos 30 anos.

${ }^{3}$ Estado moderno entendido "como forma de organização do poder históricamente determinada e, enquanto tal, caracterizada por conotações que a tornam peculiar e diversa de outras formas, historicamente também determinadas e interiormente homogêneas, de organização do poder". (SHIERA, P. In: BOBBIO, 1986, p. 425 -246).

${ }^{4}$ A respeito do caráter da universalidade, Thopson esclarece dizendo que "esto logro cultural - la tendencia a la consecución de un valor universal - tuvo uno de sus orígenes en la jurisprudencia romana."
} 
Já o direito consetudinário inglês oferecia uma interpretação alternativa da lei, sendo em alguns aspectos "más flexible y poco escrupulosa - y por ello más doblegable al <<sentido común〉> de la clase dominante - y en otros más asequible como medio a través del cual pudo hallar expresión el conflicto social, especialmente donde podía hacerse sentir el sentido de <<justicia natural $>>$ del jurado (Thompson, 2002, p. 504).

${ }^{5}$ Vale registrar que não temos a pretensão de fazermos uma Históra da Mentalidade, pois isto requereria análises mais apuradas no que se refere à aplicação das leis, aos conflitos sociais surgidos em função das suas publicações, enfim, uma outra pesquisa, o que pode vir a ser realizada posteriormente.

${ }^{6} \mathrm{O}$ common law apesar de ter surgido desde a Baixa Idade Média atendia às necessidades da emergente economia urbana e introduz a figura do jurado que representa um procedimento democrático.

${ }^{7}$ Lembramos que no Brasil, cidades eram os núcleos criados pelo rei ou por este elevadas a esta categoria. A partir de 24 de fevereiro de 1823, um decreto real eleva à categoria de cidade todas as vilas que eram capitais de províncias.

${ }^{8}$ Collecçao das Leis do Imperio do Brazil de 1832 - Parte Primeira. Rio de Janeiro: Typographia Nacional, 1874.

9 Collecçao das Decisões do Governo do Império do Brazil de 1831. Rio de Janeiro: Typographia Nacional, 1873, pp. 22 - 25 e 1876, pp. 133-134).

10 Boletim Jurídico Ano V Número 261: http://www.boletimjuridico.com.br/doutrina/texto.asp?id=1560 [ acesso em 20 de abril de 2008].

${ }^{11}$ Para melhor compreensão da importância das posturas municipais e o seu teor em relação à ordenação e regulamentação das cidades brasileiras, ver tese de doutorado de Ângela Sousa (2002) sobre as posturas municipais da cidade do Recife-PE.

12 Collecçao das Leis do Império do Brasil de 1845. Tomo VII. Parte I. Rio de Janeiro: Typographia Nacional, 1845 , p.10.

${ }^{13}$ Collecçao de Leis do Império do Brasil de 1841. Tomo IV. Parte I. Rio de Janeiro. Typographia Nacional, 1842, p. 94

${ }^{14}$ Cf. ABREU, 1997.

\section{Fontes Documentais}

Arquivo da Câmara Legislativa - Brasil - Coleção das Leis do Império (1808 - 1889) http://www2.camara.gov.br/legislacao

Arquivo do Senado Federal - Brasil - http://www6.senado.gov.br

Collecçao de Leis do Império do Brasil de 1822 a 1850. Rio de Janeiro. Typographia Nacional, 1823 - 1850.

Constituição Política do Brasil, 1824.

\section{Referências Bibliográficas}

ABREU, Maurício de Almeida. Cidade brasileira: 1870 - 1930. In: SPÓSITO, Maria Encarnação Beltrão. (org.). Urbanização e cidades: perspectivas geográficas. Presidente Prudente: UNESP/GAsPERR, 2001, p. 35 - 44.

ABREU, Maurício de Almeida. Pensando a cidade no Brasil do passado. In: SILVA, José Borzachiello, COSTA, Maria Clélisa Lustosa \& DANTAS, Eustógio Wanderley C. (Org.) A Cidade e o urbano. Forataleza: Universidade Federal do Ceará, 1997, p. 27 52.

BOBBIO, Norbert; MATTEUCCI, Nicola; PASQUINO, Gianfranco. Dicionário de Política. Brasília: Editora da Universidade de Brasília, 1986, 1328 p.

Geo UERJ. Rio de Janeiro - Ano 16, no . 25, v.2, $2^{\circ}$ semestre de 2014, pp.458-476

ISSN: 1415-7543 E-ISSN: 1981-9021

http://www.e-publicacoes.uerj.br/index.php/geouerj 
CAPEL, Horacio. La morfología de las ciudades. I- Sociedad, cultura y paisaje urbano. Barcelona: Ediciones del Serbal, 2002, 544 p.

CAPEL, Horacio. Prólogo. In: FERREIRA, Ângela Lúcia \& DANTAS, George. Surge et ambula. A construção de uma cidade moderna. Natal, 1890 - 1940. Natal: Universidade Federal do Rio Grande do Norte, 2006; s/p.

DUBY, Georges Historia social e ideologías de las sociedades. In: LE GOFF, Jacques \& NORA, Pierre (dir.). Hacer la Historia. Volumen I - Nuevos Problemas. Barcelona: Editorial Laia, 1984; p. 157 - 177.

FAORO, Raymundo Os donos do poder: formação do patronato político brasileiro. 7 ed.. Rio de Janeiro: Globo, 1987; 271 p.

HOBSBAWM, Eric. La era de la revolución, 1789 - 1848. Barcelona: Crítica, 2001; $344 \mathrm{p}$.

HOMEM, António Pedro Barbas. O espírito das instituições. Um estudo de História do Estado. Coimbra: Almedina, 2006; 253 p.

LE GOFF, Jacques. Las mentalidades. Una historia ambigua. In: LE GOFF, Jacques \& NORA, Pierre (dir.). Hacer la Historia. Volumen III - Nuevos Temas. Barcelona: Editorial Laia; 1980; p. 81-98

LE GOFF, Jacques. Pensar la historia. Modernidad, presente, progreso. Barcelona: Paidós, 1997; 269 p.

MAIA, Doralice Sátyro. Ordenamento Urbano e legislação nacional no Brasil e na Espanha (1812-1855). In: Carlos augusto de Amorim Cardoso; Doralice Sátyro Maia; Ivaine Maria Tonini; Ruth Maria da Costa Ataíde. (Org.). Territorio, Ciudad Y Educación. 1 ed. Barcelona: APEC - Asociación de Investigadores Brasileños en Cataluña, 2007, v. 1, p. 115-136.

MARX, Murilo . Cidade no Brasil: terra de quem? São Paulo: Nobel/Edusp, 1991; $143 p$.

MARX, Murilo . Cidade no Brasil em que termos? São Paulo: Studio Nobel, 1999; $143 p$.

SOUZA, Maria Ângela de Almeida. Posturas do Recife Imperial. Recife: Universidade Federal de Pernambuco, 2002. Tese. (Doutorado em História); 266 p.

THOMPSON, Edward Palmer. Obra Essencial. Barcelona: Crítica, 2002; 572 p.

Artigo recebido para publicação em setembro de 2014.

Artigo aceito para publicação em novembro de 2014.

Geo UERJ. Rio de Janeiro - Ano 16, no. 25, v.2, $2^{\circ}$ semestre de 2014, pp.458-476

ISSN: 1415-7543 E-ISSN: 1981-9021

http://www.e-publicacoes.uerj.br/index.php/geouerj 